\title{
Development of Amine Capillary Column Applied to the Analysis of Basic Compounds by Electrochromatography
}

\author{
Sabrina Flor ${ }^{1}$, Juan Martin Huala1, Valeria Tripodi1,2, Silvia Lucangioli, ${ }^{1,2}$ \\ ${ }^{1}$ Departamento de Tecnología Farmacéutica, Facultad de Farmacia y Bioquímica, Universidad de Buenos Aires, \\ Buenos Aires, Argentina \\ ${ }^{2}$ Consejo Nacional de Investigación Científica y Tecnológica (CONICET), Buenos Aires, Argentina \\ Email: slucangi@ffyb.uba.ar
}

Received 1 December 2015; accepted 25 December 2015; published 28 December 2015

Copyright (C) 2015 by authors and Scientific Research Publishing Inc.

This work is licensed under the Creative Commons Attribution International License (CC BY). http://creativecommons.org/licenses/by/4.0/

(c) (i) Open Access

\section{Abstract}

An amine capillary column was developed in a fused-silica capillary as stationary phase and applied to separation of basic compounds by capillary electrochromatography (CEC). The functionalized capillary was prepared by inmobilization of 3-Aminopropyl)triethoxysilane (APTES). The CEC conditions including APTES and buffer concentration, $\mathrm{pH}$ and applied voltage were investigated to obtain the optimal CEC system for the separation of three anesthetics as basic test molecules. The capillary column provided an efficiency of up to 20,000 plates $/ \mathrm{m}$. Lidocaine, ketamine and xilacine were baseline separated under the running conditions with $10 \mathrm{mM} \mathrm{Na}_{2} \mathrm{HPO}_{4} \mathrm{pH} 9.0$ as BGE. The applied voltage was $5 \mathrm{kV}$ temperature was set at $25^{\circ} \mathrm{C}$ and $\mathrm{UV}$ detection was performed. The resolutions were 4.97 and 1.53 for ketamine, lidocaine and xilacine, respectively. The column used in CEC mode showed better separation of the anesthetics compared with those used in the capillary zone mode. The comparison with reversed stationary phases used in HPLC in terms of resolution (Rs), sensitivity (LOD), efficiency (N), precision (RSD), asymmetry (T) was also performed. This study provided an alternative way for the CEC separation of basic compounds and demonstrated the improvement in the chromatographic parameters.

\section{Keywords}

Electrochromatography, Basic Compounds, Functionalized Capillaries

\section{Introduction}

Nowadays, basic compounds comprise among the $70 \%$ of pharmaceuticals, as well as a large percentage of

How to cite this paper: Flor, S., Huala, J.M., Tripodi, V. and Lucangioli, S. (2015) Development of Amine Capillary Column Applied to the Analysis of Basic Compounds by Electrochromatography. Journal of Analytical Sciences, Methods and Instrumentation, 5, 66-73. http://dx.doi.org/10.4236/jasmi.2015.54008 
compounds with biomedical and biological significance. Although, liquid chromatography is the main tool for the analysis of basic compounds in several areas, the analysis of basic compounds remains as a field which presents several difficulties. Since bonded stationary phases were developed, reversed phase (RP) separation became the most important tool in liquid chromatography. Many different stationary phases with diverse surface modifications have been designed and developed up to now, according to the nature and requirements for the separation of compounds. But despite the evolution in column technologies, as many as $50 \%$ of silanol groups remains unreacted in the surface of silica packing in a traditional RP column [1] [2].

Many tools have been employed to overcome problems associated to separation of basic compounds, by reducing or suppressing the detrimental effects of the interaction with free silanols groups. As it was described by [3] one of the options is to change the bonding chemistry or work with non-silica based stationary phases. But one of the most common solutions is to add silanol masking agents (such as amines, e.g. TEA) to the mobile phase. Separation with mobile phases at $\mathrm{pH}$ above 10 is another especially attractive alternative, since at $\mathrm{pH}$ over 9 many of them exist as free bases, minimizing problems of interactions with ionized silanol groups on the silica support. However, column packings especially designed to operate at higher $\mathrm{pH}$ values must be used, and these materials have not reached a high level of acceptance because of problems with reproducibility and efficiency, mostly [2].

Capillary electrochromatography (CEC) has attracted increasing attention in recent years due to its efficiency in micro-analysis. CEC is a hybrid technique that combines the interaction between the analytes and the stationary phase bonded to the capillary wall, as occurs in HPLC, with the advantages of capillary electrophoresis (CE), like the use of the electro-osmotic flow instead of a mechanical pump, which generates high separation efficiencies [4]. One of the modes of CEC, is Open-tubular capillary electrochromatography (OT-CEC) where the inner wall of a fused silica capillary is covalently bonded to different stationary phases. In OT-CEC, the low phase ratio provides shorter analysis times and higher separation efficiencies which makes the technique attractive [5].

The aim of this work was to develop a capillary column functionalized with an amine group, to be applied to the analysis of basic compounds as an alternative method, by comparing it with conventional reversed stationary phases in term of resolution, sensitivity, efficiency, precision, using as test amine molecules three anesthetics agents: lidocaine, xylazine and ketamine (Figure 1).

\section{Materials and Methods}

Xylazine hydrochloride (N-(2,6-Dimethylphenyl)-5,6-dihydro-4H-1,3-thiazin-2-amine hydrochloride), ketamine hydrochloride (2-(2-chlorophenyl)-2-(methylamino)cyclohexan-1-one; hydrochloride), lidocaine hydrochloride (2-(diethylamino)-N-(2,6-dimethylphenyl)acetamide; hydrochloride), (3-Aminopropyl)triethoxysilane (APTES) were supplied by Sigma (St. Louis, MO, USA). Disodium hydrogen phosphate, acetic acid, hydrochloric acid, sodium hydroxide and acetonitrile (HPLC grade) were purchased from Merck (Darmstadt, Germany). Water was purified in an EASYPuretmRF equipment (Barnstead, Dubuque, IA, USA).<smiles>CCN(CC)CC(=O)Nc1c(C)cccc1C</smiles>

I<smiles>CNC1(c2ccccc2Cl)CCCCC1=O</smiles>

III<smiles>Cc1cccc(C)c1NC1=NCCCS1</smiles>

II

Figure 1. Chemical structure of (I) lidocaíne, (II) xylazine and (III) ketamine. 


\subsection{Instruments}

HPLC analysis was performed using a Thermo Scientific HPLC (Waltham, MA, USA) equipped with a quaternary pump (P4000), a temperature controller, a vacuum degasser (SCM 1000), a dual UV detector (UV2000), an automatic injector (AS3000) and ChromQuest 5.0 software. Four different RP HPLC columns were tested. Determination of lidocaine, xylazine and ketamine was performed using two Hypersil BDS C18 Columns $250 \times$ $4.6 \mathrm{~mm}$ i.d., $5 \mu \mathrm{m}$ particle size and, $100 \times 2.0 \mathrm{~mm}$ i.d, $2.4 \mu \mathrm{m}$ particle size (Thermo Fisher Scientific Inc. Waltham, MA USA), and two Symmetry C18 Column $150 \times 4.6 \mathrm{~mm}$ i.d., $5 \mu \mathrm{m}$ particle size and $7.5 \times 4.6 \mathrm{~mm}$ i.d., 3.5 particle size (Waters, Milford, MA, USA). For the simultaneous determination of the three anesthetics, the isocratic mobile phase consisted of a mixture of acetonitrile: $3 \%$ Acetic acid $\mathrm{pH} 3.4(80: 20 \mathrm{v} / \mathrm{v})$. Flow rate and injection volume were different for each system. UV-detection was performed at $210 \mathrm{~nm}$. Chromatographic conditions were applied according to USP 31 [6] (Table 1). IR spectrums were obtained with a spectrophotometer IR Nicolet 380 (Thermo Fisher Scientific Inc. Waltham, MA USA).

All CE and CEC separations were performed using a P/ACETM MDQ CE system (Beckman, Fullerton, CA, USA). Uncoated fused silica capillaries (Microsolv Technology, Eatontown, NJ, USA) of $32 \mathrm{~cm}(22 \mathrm{~cm}$ length to detector) $\times 75 \mu \mathrm{m}$ id., were chemically modified with (3-aminopropyl) triethoxysilane. The separation was performed by a system consisting of disodium hydrogen phosphate $10 \mathrm{mM} \mathrm{pH} \mathrm{9.0,} \mathrm{which} \mathrm{constituted} \mathrm{the} \mathrm{back-}$ ground electrolyte (BGE). Capillary temperature was kept at $25^{\circ} \mathrm{C}$, and $\mathrm{UV}$ detection was set at $210 \mathrm{~nm}$. Samples were injected under 0.3 psi pressure for 3 seconds (equal to $16.89 \mathrm{~nL}$ according to Beckman CE Expert 1.0) and the electrophoretic system was operated under positive polarity at a constant voltage of $5 \mathrm{kV}$. Before each analysis and between runs, the capillary was washed with BGE for 2 minutes.

\subsection{Standard Solution}

For each individual standard solution of the amine compounds $85 \mathrm{mg}$ were accurately weighed in $0.5 \mathrm{~mL}$ of $1 \mathrm{~N}$ hydrochloric acid in a $50.0 \mathrm{~mL}$ volumetric flask, diluted to volume and mixed [6]. To prepare a standard solution containing the three analytes, 5.0 milliliters of each solution were transferred to $50.0 \mathrm{~mL}$ volumetric flask, made up to volume with mobile phase to get $170 \mu \mathrm{g} / \mathrm{mL}$ of each one.

\subsection{Capillary Derivatization}

Capillary derivatization procedure was based on previous reports [7]. An uncoated fused silica capillary of 32 $\mathrm{cm}$ length and $75 \mu \mathrm{m}$ internal diameter was firstly activated with $\mathrm{NaOH} 0.5 \mathrm{M}, \mathrm{NaOH} 0.1 \mathrm{M}$, distilled water and methanol by rinsing with pressure for 5 minutes at 0.5 psi. After activation, the capillary is then silanized by filling with a methanol: (3-aminopropyl)triethoxysilane solution (1:1) and sealed with two GC septa. The capillary was kept 24 hours at $70^{\circ} \mathrm{C}$. After that, the capillary was rinsed with methanol to eliminate the residual reagents and dried with nitrogen (Figure 2).

\section{Results and Discussion}

\subsection{Derivatization of the Capillary}

The silanization procedure was optimized based on a previous report of Yuan et al. [7] who functionalized the capillary wall with 3-(methacryloxy)propyltriethoxysilane for the further obtention of a poly $\beta$-CD modified monolith.

In our work, during the optimization steps, the influence of different solvents, besides methanol, was evaluated on the silanization procedure (acetonitrile and dimethylformamide) but no result was satisfactory. Also, time as well as temperature, were evaluated. Different assays were carried out during 3, 6, 8 or 24 hours, at 60,

Table 1. Flow rate and injection volume.

\begin{tabular}{ccccc}
\hline \multirow{2}{*}{ Column } & \multicolumn{2}{c}{ Hypersil BDS C18 } & \multicolumn{2}{c}{ Symmetry C18 } \\
\cline { 2 - 5 } & $250 \times 4.6 \mathrm{~mm}, 5 \mu \mathrm{m}$ & $100 \times 2.0 \mathrm{~mm}, 2.4 \mu \mathrm{m}$ & $150 \times 4.6 \mathrm{~mm}, 5 \mu \mathrm{m}$ & $75 \times 4.6 \mathrm{~mm}, 3.5 \mu \mathrm{m}$ \\
\hline Flow rate $(\mathrm{mL})$ & 1.5 & 0.3 & 1.5 & 1.5 \\
Injection volume $(\mu \mathrm{L})$ & 20 & 5 & 5 & 5 \\
\hline
\end{tabular}




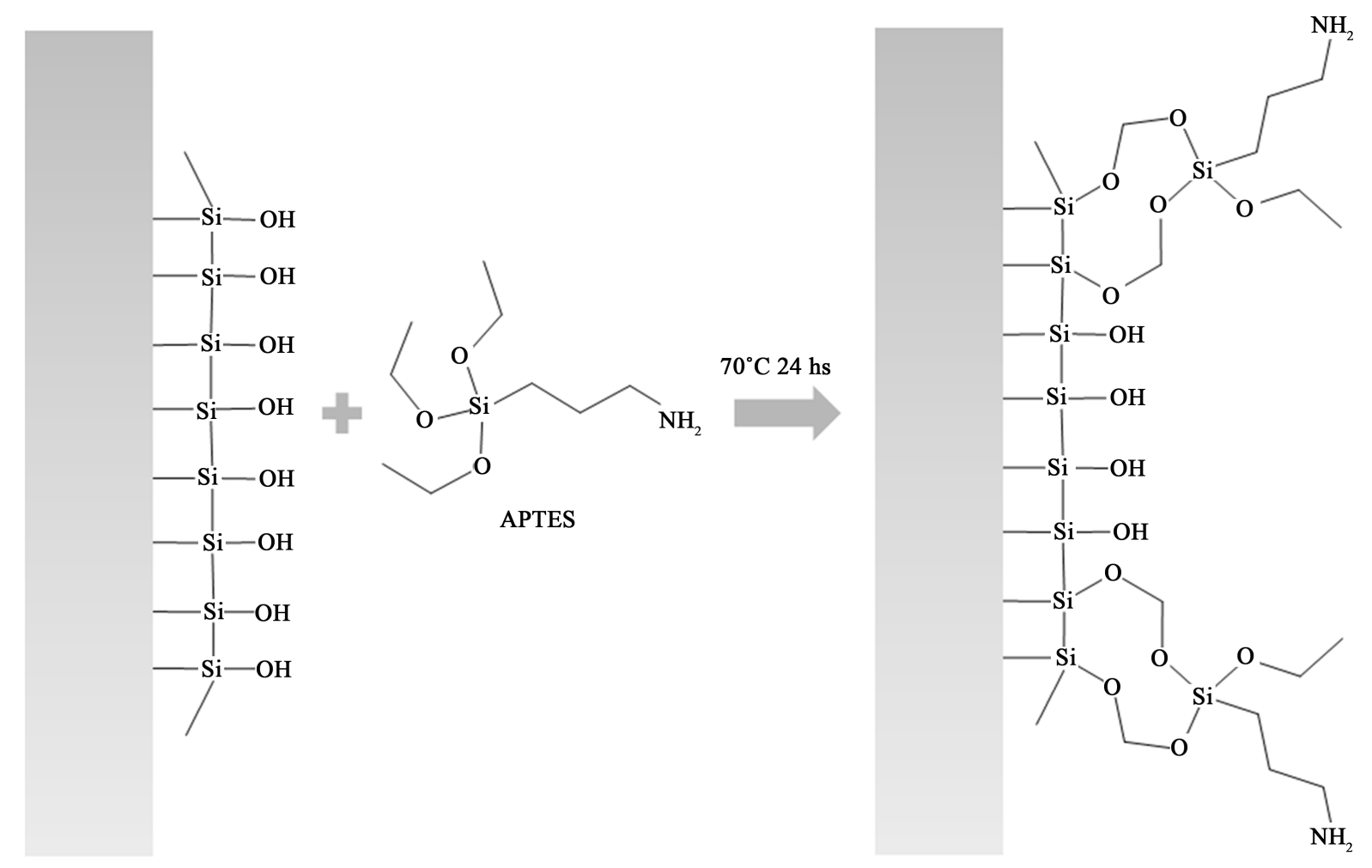

Figure 2. Scheme of capillary derivatization procedure.

$70^{\circ} \mathrm{C}$ or $80^{\circ} \mathrm{C}$ (Section 2.3). Finally, a mixture of methanol: APTES (1:1), at $70^{\circ} \mathrm{C}$ for 24 hs in a glycerin bath were chosen as the optimal conditions to obtain a stable functionalized capillary column. To ascertain the modification of the surface of the capillary inner wall, the IR spectra of a pulverized bare capillary and a capillary after derivatization were compared (Figure 3).

In order to evaluate inter and intra-day for each capillary, and also "capillary to capillary" reproducibility, two assays were carried out. For intra and inter day reproducibility, no changes were observed in the migration time of the test compounds in at least 50 injections (RSD below 0.6 and 1.1 respectively) with 2 minutes of capillary rinsing between injections (In Figure 4 can be observed 10 injections of the 50). On the other hand, to assess "capillary to capillary" reproducibility three capillaries were derivatized under the exact same conditions. Then 10 injections of a standard solution were performed in each capillary, and RSD value was less than 1.5 percent between capillaries (comparison of the average migration time and peak area).

\subsection{Evaluation of the Capillary Performance}

Firstly, capillary performance was evaluated by comparing the separation of the test compounds in a bare capillary and the modified one. As can be seen in Figure 5, complete baseline resolution in a short time with very good peak shape was achieve in the modified capillary contrary to what takes place in the bare capillary. But not only resolution was improved, migration order of the analytes was also altered in accordance with the one obtained using a reversed HPLC phase.

The separation of the test molecules in the amine modified capillary column shows very good RSD and resolution values, quite similar, and in some cases even better, than those obtained with HPLC. But the most important aspect was the remarkable results obtained for tailing factor $(\mathrm{T})$ values, which are comparable to those obtained with Symmetry columns. These low $\mathrm{T}$ values demonstrate that the capillary wall derivatization reduces the number of ionizablesilanols, reducing the interaction with the amine groups present in the molecules. Moreover, efficiency was over 10 times higher than for the other systems. The other remarkable parameter is the sensitivity obtained using the amine capillary column, with LOD values below 5 femtograms on column.

Chromatographic and electrophoretic parameters such as precision (expressed as RSD of $n=10$ ), resolution 


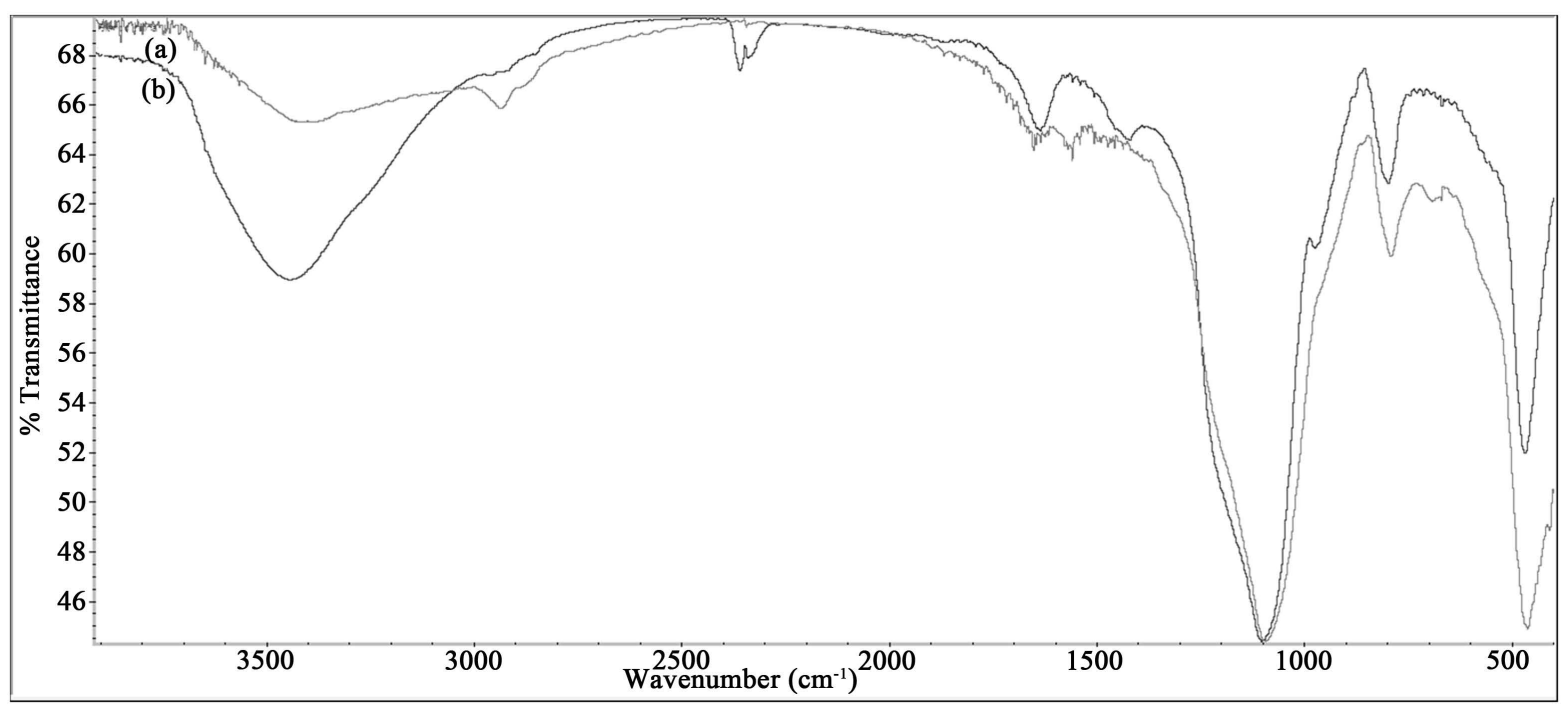

Figure 3. IR spectrum of (a) a modified capillary and (b) a bare capillary.

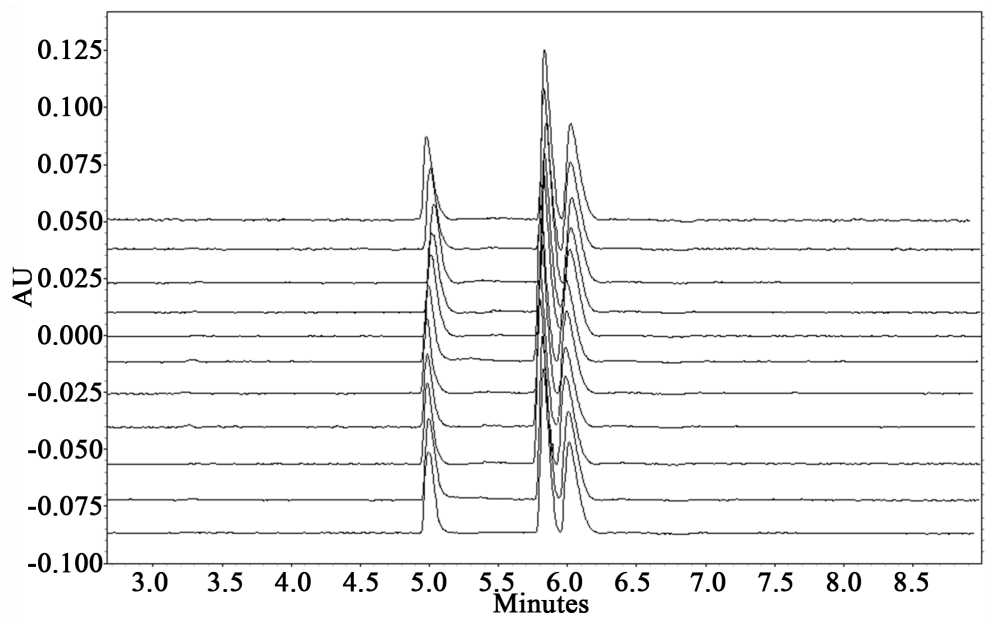

Figure 4. Ten consecutive injections of lidocaine, ketamine and xylazine standard.

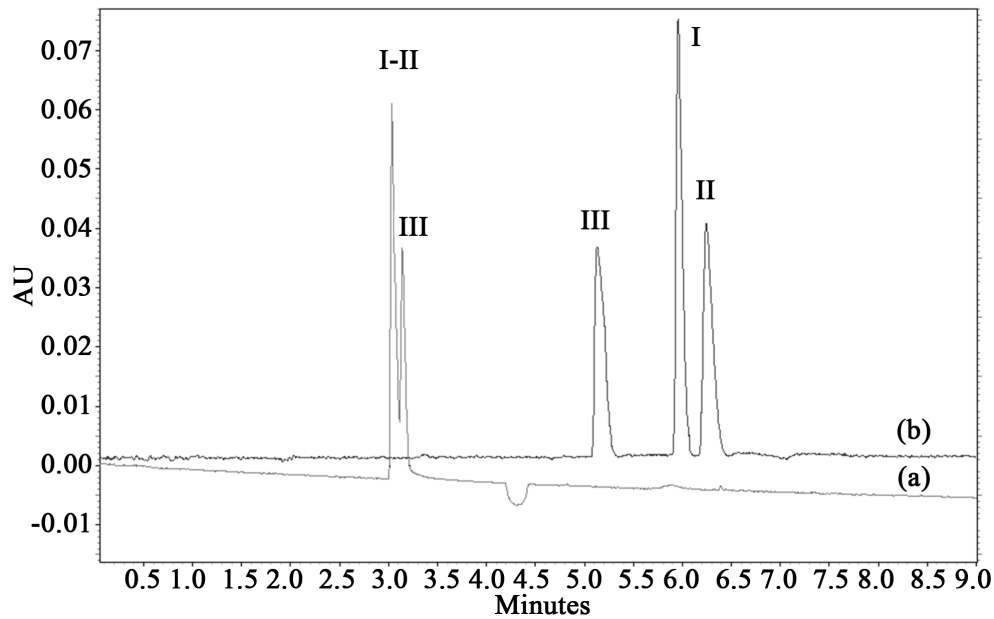

Figure 5. Separation of (I) lidocaine, (II) xylazine and (III) ketamine performed using (a) uncoated fused silica capillary and (b) capillary chemically modified with (3-aminopropyl) triethoxysilane. 
(Rs), sensitivity (LOD), asymmetry (T), efficiency (N), selectivity $(\alpha)$, with $(\mathrm{W})$ were calculated according to USP (The United States Pharmacopeia, Thirty-First Revision, 2008) and compared (Table 2).

As it can be seen in the data of Table 2 and Figure 6(a), in the analysis of these three amine compounds according to the official USP method, the obtained T values are not acceptable even though the internal diameter and particle size were reduced. Furthermore, although the use of Symmetry columns (special RP column applied to analyze basic compounds) clearlyimproves the peak shape (Figure 6(c) and Figure 6(d)), only one of such T values below 2 are obtained (Table 2).

Table 2. Chromatographic and electrophoretic parameters.

\begin{tabular}{|c|c|c|c|c|c|c|}
\hline & \multirow{2}{*}{ Column } & \multicolumn{2}{|c|}{ Hypersil BDS C18 } & \multicolumn{2}{|c|}{ Symmetry C18 } & \multirow{2}{*}{$\begin{array}{l}\text { Amine Capillary } \\
320 \times 0.075 \mathrm{~mm}\end{array}$} \\
\hline & & $\begin{array}{c}250 \times 4.6 \mathrm{~mm} \\
5 \mu \mathrm{m}\end{array}$ & $\begin{array}{c}100 \times 2.0 \mathrm{~mm} \\
2.4 \mu \mathrm{m}\end{array}$ & $\begin{array}{c}150 \times 4.6 \mathrm{~mm} \\
5 \mu \mathrm{m}\end{array}$ & $\begin{array}{c}75 \times 4.6 \mathrm{~mm} \\
3.5 \mu \mathrm{m}\end{array}$ & \\
\hline \multirow{8}{*}{ Ketamine } & $\mathrm{RSD}^{\mathrm{a}}$ & 1.73 & 3.34 & 1.58 & 0.19 & 0.36 \\
\hline & $\mathrm{Rs}^{\mathrm{b}}$ & 0.56 & 0.88 & 1.26 & 1.30 & 4.97 \\
\hline & LOD (pgoncolumn) & 3.9 & 1.02 & 7.70 & 7.60 & 0.0043 \\
\hline & $\mathrm{K}^{\prime}$ & 1.27 & 3.55 & 1.11 & 1.28 & 1.40 \\
\hline & A & 1.13 & 1.15 & 1.18 & 1.23 & 1.17 \\
\hline & $\mathrm{W}$ & 0.52 & 0.65 & 0.16 & 0.12 & 0,12 \\
\hline & $\mathrm{T}$ & 2.7 & 1.8 & 1.1 & 1.3 & 1.5 \\
\hline & $\mathrm{N}$ & 1030 & 1063 & 3268 & 2138 & 40,009 \\
\hline \multirow{8}{*}{ Lidocaine } & $\mathrm{RSD}^{\mathrm{a}}$ & 0.26 & 2.97 & 1.48 & 0.14 & 0.36 \\
\hline & $\mathrm{Rs}^{\mathrm{c}}$ & 2.21 & 3.42 & 3.41 & 2.71 & 1.53 \\
\hline & LOD (pgoncolumn) & 2.00 & 0.70 & 3.90 & 4.10 & 0.0053 \\
\hline & $K^{\prime}$ & 1.43 & 4.08 & 1.31 & 1.57 & 1.20 \\
\hline & A & 1.93 & 1.03 & 1.58 & 1.73 & 1.03 \\
\hline & $\mathrm{W}$ & 0.81 & 0.71 & 0.19 & 0.15 & 0.23 \\
\hline & $\mathrm{T}$ & 3.2 & 1.6 & 1.3 & 1.7 & 1.8 \\
\hline & $\mathrm{N}$ & 607 & 1159 & 2820 & 1732 & 20,290 \\
\hline \multirow{8}{*}{ Xylazine } & $\mathrm{RSD}^{\mathrm{a}}$ & 0.64 & 3.41 & 1.91 & 0.23 & 0.40 \\
\hline & Rs & DNA & DNA & DNA & DNA & DNA \\
\hline & LOD (pgoncolumn) & 0.30 & 0.09 & 0.50 & 0.50 & 0.0038 \\
\hline & $K^{\prime}$ & 2.77 & 6.65 & 2.08 & 2.72 & 1.16 \\
\hline & A & DNA & DNA & DNA & DNA & DNA \\
\hline & $\mathrm{W}$ & 1.71 & 1.04 & 0.29 & 0.36 & 0.17 \\
\hline & $\mathrm{T}$ & 3.9 & 2.8 & 1.3 & 2.5 & 1.6 \\
\hline & $\mathrm{N}$ & 287 & 1232 & 2054 & 612 & 7988 \\
\hline
\end{tabular}

Chromatographic parameters calculated according to USP 31 [8]. Electrophoretic parameters calculated according to Rathore et al. [9]. ${ }^{\text {a RSD calcu- }}$ lated based on $\mathrm{n}=10$. Resolution between ${ }^{\mathrm{b}}$ ketamine-lidocaine and ${ }^{\mathrm{C}}$ lidocaine-xylazine. (DNA = does not apply). 


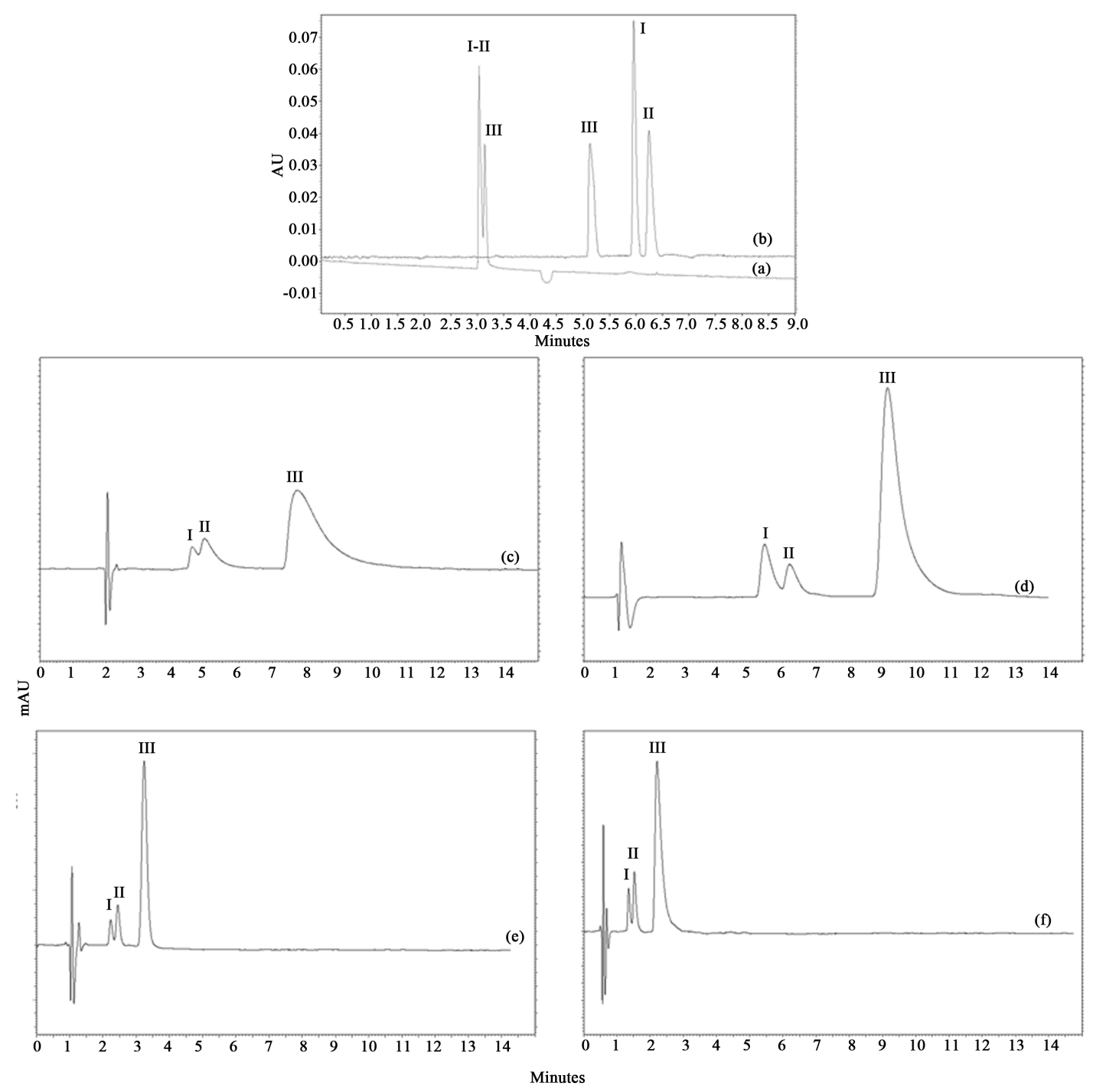

Figure 6. Separation of (I) lidocaine, (II) xylazine and (III) ketamine performed using (a) Uncoated fused silica capillary and (b) Capillary chemically modified with (3-aminopropyl)triethoxysilane, (c) Hypersil BDS C18 Columns $250 \times 4.6$ mm i.d., 5 $\mu$ m particle size (d) Hypersil BDS C18 Columns $100 \times 2.0 \mathrm{~mm}$ i.d, $2.4 \mu \mathrm{m}$ particle size, (e) Symmetry C18 Column $150 \times$ $4.6 \mathrm{~mm}$ i.d., $5 \mu \mathrm{m}$ particle size and (f) Symmetry C18 Column $7.5 \times 4.6 \mathrm{~mm}$ i.d., 3.5 particle size.

\section{Concluding Remarks}

The developed amine capillary column presents good parameters in terms of resolution, sensitivity, asymmetry, efficiency and precision in the analysis of amine test molecules. The preparation of the functionalized stable amine column was easy and it could be considered as a simple and low cost attractive alternative for the analysis of basic compounds in pharmaceutical and biochemical analysis.

\section{References}

[1] Kirkland, J.J. (2004) Development of Some Stationary Phases for Reversed-Phase High-Performance Liquid Chromatography. Journal of Chromatography A, 1060, 9-21. http://dx.doi.org/10.1016/S0021-9673(04)01892-8

[2] McCalley, D.V (2010) The Challenges of the Analysis of Basic Compounds by High Performance Liquid Chromatography: Some Possible Approaches for Improved Separations. Journal of Chromatography A, 1217, 858-880. http://dx.doi.org/10.1016/j.chroma.2009.11.068

[3] Ruiz-Angel, M.J., Carda-Broch, S. and Berthod, A. (2006) Ionic Liquids versus Triethylamine as Mobile Phase Addi- 
tives in the Analysis of $\beta$-Blockers. Journal of Chromatography A, 1119, 202-208. http://dx.doi.org/10.1016/j.chroma.2005.11.132

[4] Al-Hussin, A., Boysen, R.I., Saito, K. and Hearn, M.T.W. (2014) Preparation and Electrochromatographic Characterization of New Chiral $\beta$-Cyclodextrin Poly(acrylamidopropyl) Porous Layer Open Tubular Capillary Columns. Journal of Chromatography A, 1358, 199-207.

[5] Olsson, J. and Blomberg, L.G. (2008) Enantioseparation of Omeprazole and Its Metabolite 5-Hydroxyomeprazole Using Open Tubular Capillary Electrochromatography with Immobilized Avidin as Chiral Selector. Journal of Chromatography B: Analytical Technologies in the Biomedical and Life Sciences, 875, 329-332. http://dx.doi.org/10.1016/j.jchromb.2008.05.050

[6] The United States Pharmacopeia, T.-F.R. (2008) Lidocaine. 2527-2528.

[7] Yuan, R., Wang, Y. and Ding, G. (2010) Enantiomeric Separation by Capillary Electrochromatography on a Sulfated Poly $\beta$-Cyclodextrin Modified Silica-Based Monolith. Analytical Sciences: The International Journal of the Japan Society for Analytical Chemistry, 26, 943-947. http://dx.doi.org/10.2116/analsci.26.943

[8] The United States Pharmacopeia, T.-F.R. (2008) Physical Test <621>. 232-243.

[9] Rathore, A.S. and Horváth, C. (1996) Separation Parameters via Virtual Migration Distances in High-Performance Liquid Chromatography, Capillary Zone Electrophoresis and Electrokinetic Chromatography. Journal of Chromatography A, 743, 231-246. http://dx.doi.org/10.1016/0021-9673(96)00306-8 